\title{
Development of an Electrochemical Sensing System for Wine Component Analysis
}

Parvin Begum $^{\mathrm{a}^{*}}$, Tatsuya Morozumi ${ }^{\mathrm{a}}$, Toshikazu Kawaguchi ${ }^{\mathrm{a}, \mathrm{b}}$, Teruo Sone $^{\mathrm{b}, \mathrm{c}}$

${ }^{a}$ Faculty of Environmental Earth Sciences, Hokkaido University, Sapporo 060-0810, Japan

${ }^{\mathrm{b}}$ Graduate School of Global Food Resources, Hokkaido University, Sapporo 060-8589, Japan

${ }^{c}$ Faculty of Agriculture, Hokkaido University, Sapporo 060-8589, Japan

\section{Table of contents:}

Figure S1 (a) Performance graph of Peltier cooler; (b) Heating curve of wine under peltier system. S-2

Figure S2: CV of (a) blank, red wine and increasing amount of $\mathrm{SO}_{2}(3 \mathrm{ppm}, 6 \mathrm{ppm}$ and $9 \mathrm{ppm}$ ) (b) calibration curve of $\mathrm{I}_{\mathrm{p}, \mathrm{a}}$ versus concentration (ppm)... S-3

Figure S3: CV of (a) white wine and white wine + catechol; (b) red wine and red wine + acetaldehyde; (c) white wine and white wine + acetaldehyde S-4,5

Figure S4: CV of (a) different white wines from different producers; (b) white Niagara and white Riesling S-6 

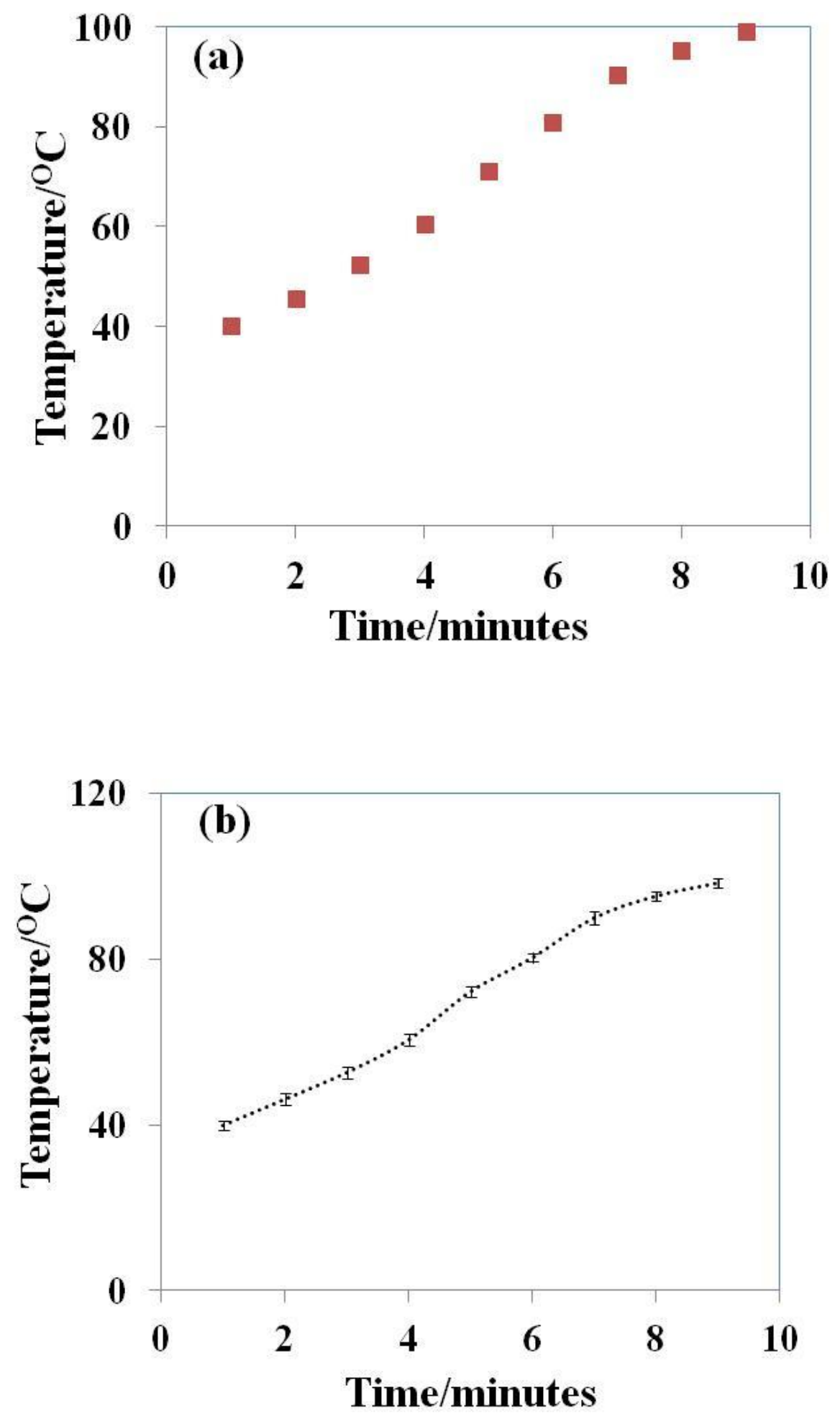

Figure S1 (a) Performance graph of Peltier cooler; (b) Heating curve of wine under peltier system. 

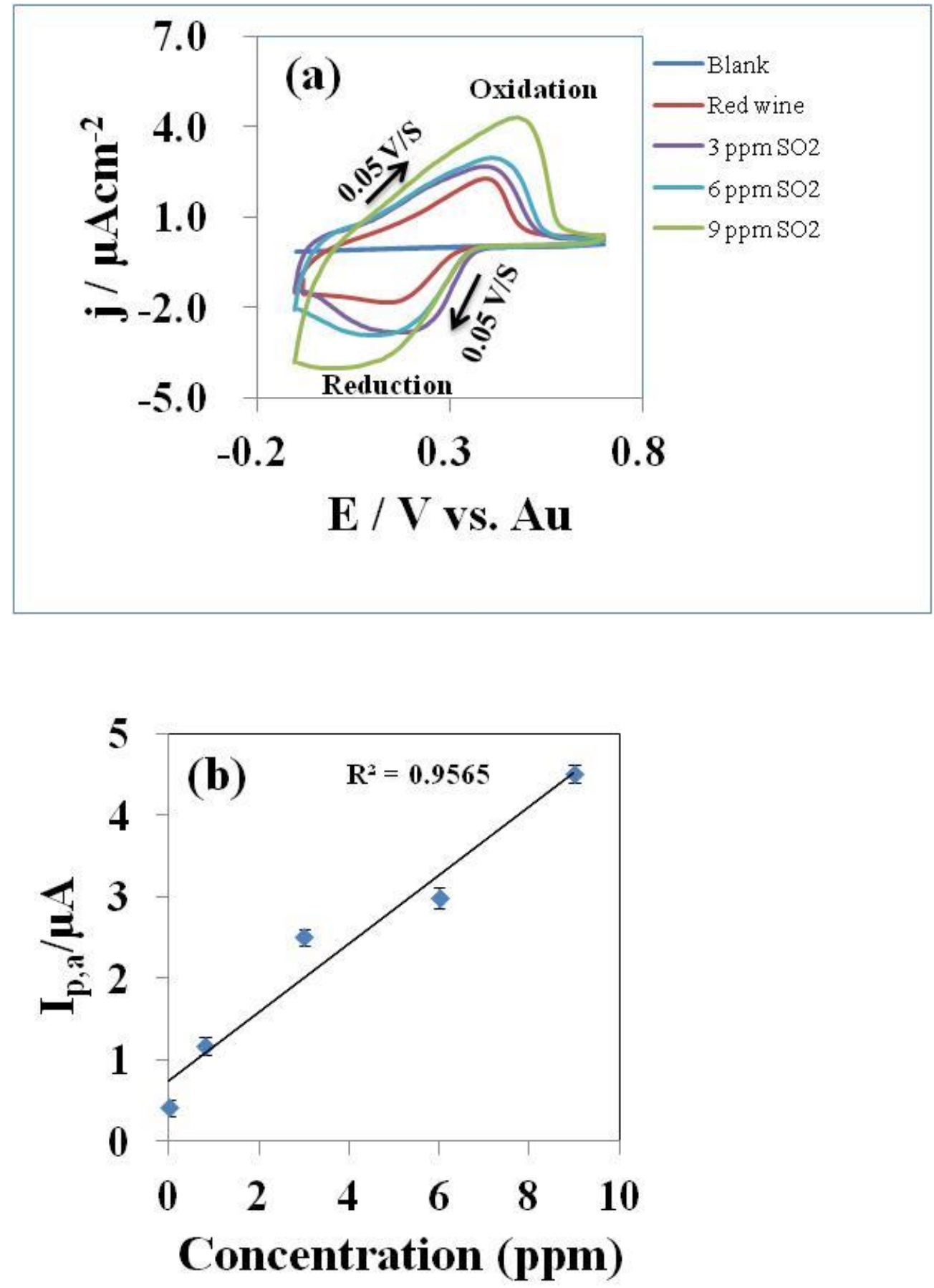

Figure $\mathrm{S} 2$ : $\mathrm{CV}$ of (a) blank, red wine and increasing amount of $\mathrm{SO}_{2}(3 \mathrm{ppm}, 6 \mathrm{ppm}$ and $9 \mathrm{ppm}$ ) (b) calibration curve of $\mathrm{I}_{\mathrm{p}, \mathrm{a}}$ versus concentration (ppm). 

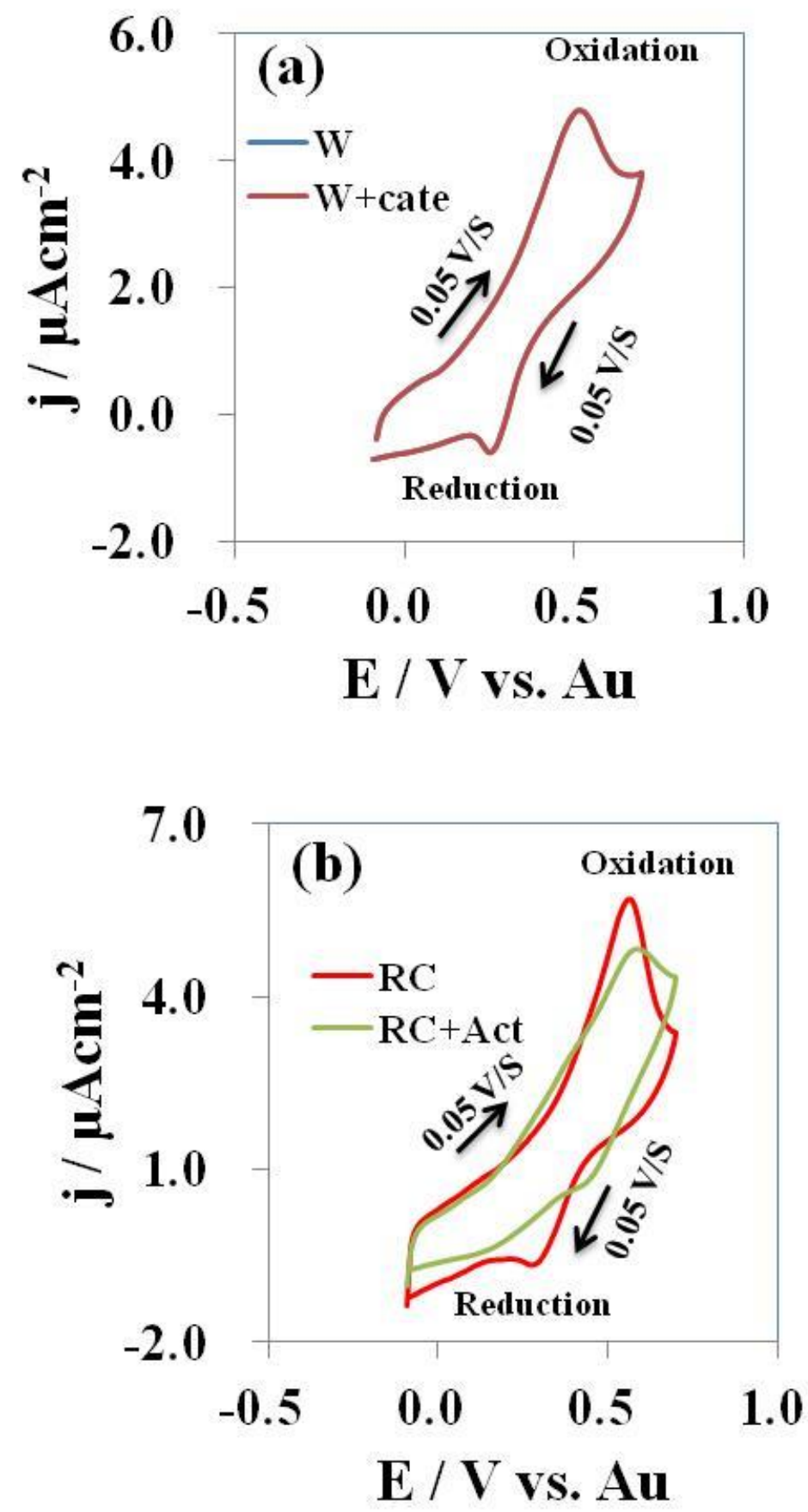


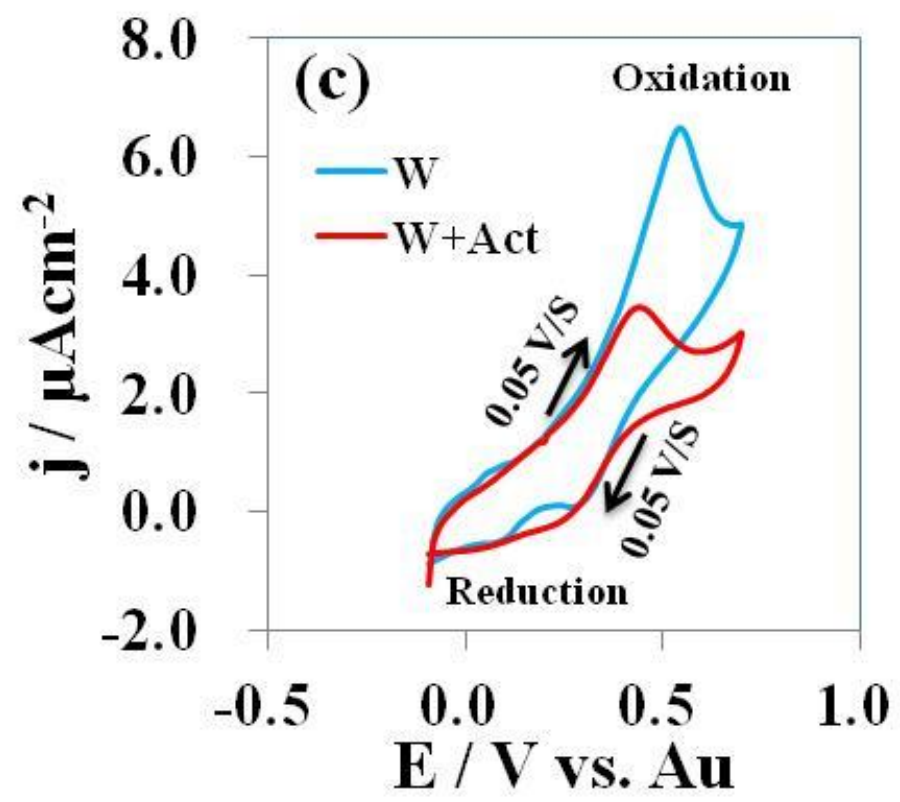

Figure S3: CV of (a) white wine and white wine + catechol; (b) red wine and red wine + acetaldehyde; (c) white wine and white wine + acetaldehyde 

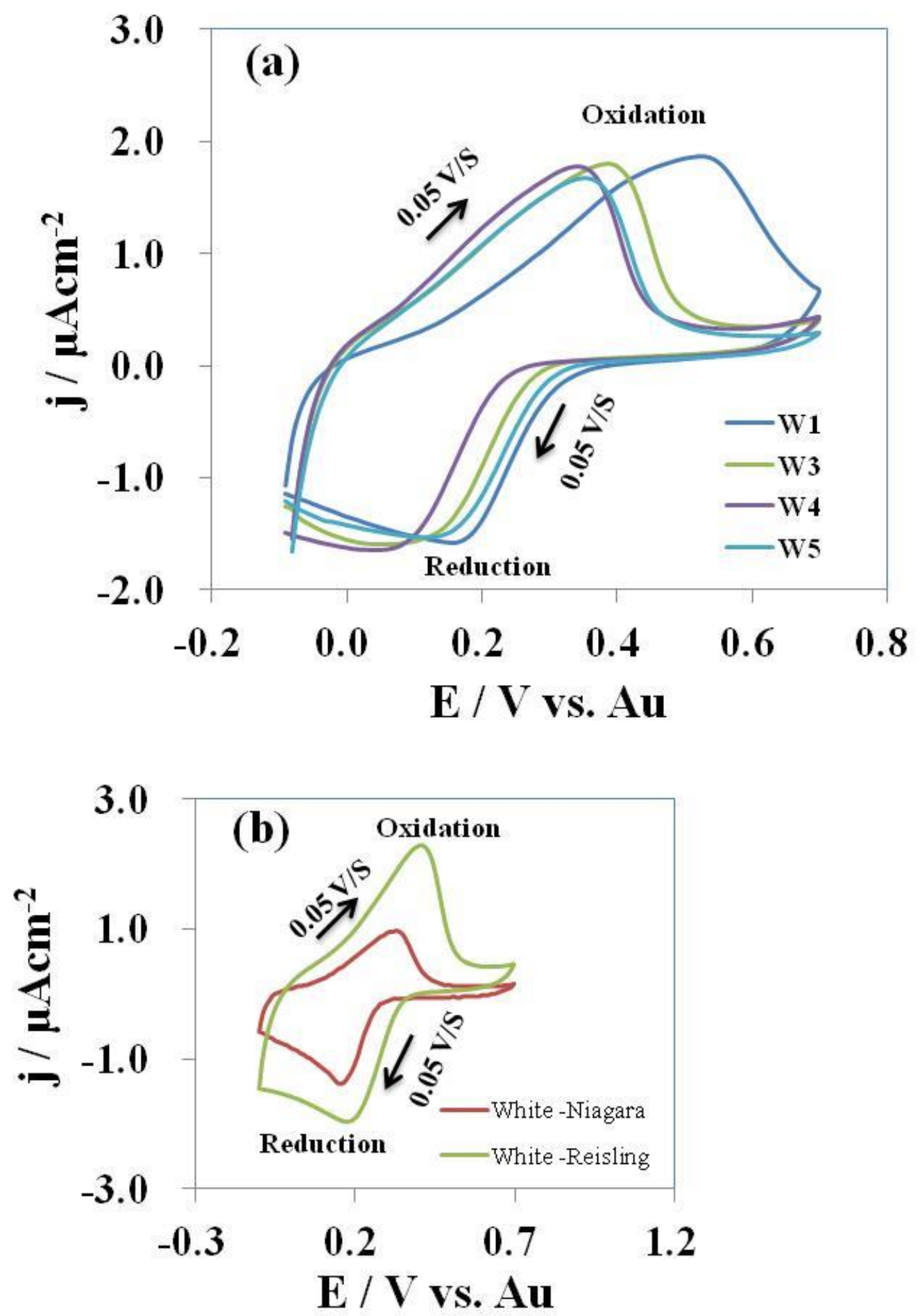

Figure S4: CV of (a) different white wines from different producers; (b) white Niagara and white Riesling. 